\title{
Holocentric chromosome evolution in kissing bugs (Hemiptera: Reduviidae: Triatominae): diversification of repeated sequences
}

Sebastián Pita ${ }^{1}$, Pedro Lorite ${ }^{2}$, Jesús Vela², Pablo Mora², Teresa Palomeque ${ }^{2}$, Khoa Pham Thi ${ }^{3}$ and Francisco Panzera ${ }^{1 *}$

\begin{abstract}
Background: The analysis of the chromosomal and genome evolution in organisms with holocentric chromosomes is restricted by the lack of primary constriction or centromere. An interesting group is the hemipteran subfamily Triatominae, vectors of Chagas disease, which affects around 6 to 7 million people worldwide. This group exhibits extensive variability in the number and chromosomal location of repeated sequences such as heterochromatin and ribosomal genes. This paper tries to reveal the significant differences of the repeated sequences among Triatoma species through the use of genomic DNA probes.

Methods: We analysed the chromosomal distribution and evolution of repeated sequences in Triatoma species by genomic in situ hybridization (GISH) using genomic DNA probes from two North American Triatoma species. These genomic probes were hybridized both on their own chromosomes and on other Triatoma species from North and South America, with different amounts and chromosome location of C-heterochromatin. The results were compared with those previously described using South American Triatoma genomic probes.

Results: We observed two chromosomal hybridization patterns: (i) very intense hybridization signals concentrated on specific chromosomal regions or particular chromosomes; and (ii) lower intensity hybridization signals dispersed along all chromosomes. Self-GISH on T. rubrofasciata and T. dimidiata chromosomes presented strong hybridization signals on all C-heterochromatin regions. However, when we perform genomic cross-hybridizations, only strong signals are detected on the $Y$ chromosome, leaving the C-heterochromatic autosomal regions unmarked.

Conclusions: We confirm that repeated DNA of the $Y$ chromosome is shared among Triatoma species and probably represents an ancestral character of the Triatomini tribe. On the contrary, autosomal heterochromatic regions are constituted by species-specific DNA repeats, most probably satDNA families, suggesting that Triatoma speciation involved the amplification of diverse types of autosomal repeats. Molecular characterization of principal repetitive DNAs seems to be an appropriate approach to infer evolutionary relationships in triatomines.
\end{abstract}

Keywords: Chagas disease vectors, Genomic in situ hybridization, Holocentric chromosomes, Triatominae

\footnotetext{
* Correspondence: fcopanzera@gmail.com

'Sección Genética Evolutiva, Facultad de Ciencias, Universidad de la

República, Calle Iguá 4225, 11400 Montevideo, Uruguay

Full list of author information is available at the end of the article
} 


\section{Background}

Repetitive DNA sequences consist of a large portion of eukaryotic genomes including tandem and dispersed repeats $[1,2]$. Tandem repeats are organized in arrays in which the monomers (or repeat units) are repeated in a head-to-tail fashion, including multigene families (ribosomal DNAs, histone genes and small nuclear DNA) and satellite DNA (satDNA). Dispersed repeats are mainly represented by transposable elements, which are DNA segments able to change from one locus to another within the genome of their host [3].

Repetitive DNA fractions are usually larger than the coding sequence component of a genome and are essential for different genomic functions such as replication, transcription and expression [4]. For example in Drosophila, the important role that heterochromatin plays in the chromosome pairing, gene silencing via position-effect variegation and maintaining genome stability is well documented [5]. The chromosomal distribution of repeated DNA sequences, mainly located in the heterochromatic regions, confers a specific nuclear architecture, which establishes distinct transmission and expression characteristics even with the same coding sequences [4]. Hence, alterations in the location and composition of repeated DNA would have a diversification role in the evolution of the species [6], such as it was observed in the reproductive isolation of Drosophila sister species [7]. Evolutionary analyses of these sequences are even more significant in organisms with holocentric chromosomes, where karyotypes generally lack appropriate chromosomal markers for this type of study. In insects, different orders that include species with significant economic (agricultural pests) and medical importance (vectors of human diseases) exhibit this type of chromosomes. These orders are Dermaptera (earwigs), Hemiptera (true bugs), Lepidoptera (butterflies and moths), Odonata (dragonflies and damselflies), Phthiraptera (lice), Psocoptera (book lice), Zoraptera (angel insects) and Trichoptera (cloth moths) [8]. In the Hemiptera, the reduviid subfamily Triatominae comprises vectors for Chagas disease, an anthropozoonotic illness caused by the protozoan parasite Trypanosoma cruzi, which affects six to seven million people worldwide, mostly in Latin America but is increasingly detected in USA, Canada, and many European countries [9]. In this hemipteran group, the lack of primary constriction and their small chromosome size greatly hamper chromosome studies. Although their holokinetic structure is expected to facilitate karyotype evolution through fusions and chromosome fissions, the number of autosomes in triatomines appears to be quite stable: almost all species have a diploid autosomal number of 20 [10]. In spite of this extensive uniformity in their autosomal number, the subfamily Triatominae exhibits a great variability of the genome size [11], in the ribosomal clusters chromosome location [12-14] and in the amount, distribution and composition of the repetitive sequences included in the constitutive heterochromatin $[10,15]$. Nevertheless, unlike other insects or even other hemipteran families such as Coreidae or Pentatomidae, FISH analyses using other multigene families' probes such as $5 \mathrm{~S}$ rDNA, U2 snDNA or histone genes, failed to achieve satisfactory results in this insect group. In this way, different methodological approaches were applied to analyse repetitive sequences of triatomines such as genomic in situ hybridization (GISH) [16] and chromosomal microdissection [17]. In insects with holocentric chromosomes, GISH approaches are scarce and have been applied to the study of sex chromosomes evolution in the Lepidoptera (reviewed by [18]) and Hemiptera (Pyrrhocoridae) [19]. A previous GISH study using genomic probes of Triatoma species from South America revealed that closely related species share their repetitive sequences. Furthermore, all Triatomini tribe species, including Triatoma and other genera, always have a Y chromosome with similar highly repeated sequences [16]. To further analyse the evolution of the repeated sequences both in autosomes and sex chromosomes in the genus Triatoma, in this paper we applied genomic probes from two North American Triatoma species. These DNA probes were hybridized both on their own chromosomes (self-GISH) and on other Triatoma species, with different amount and chromosomal location of the C-heterochromatin.

\section{Methods}

The subfamily Triatominae includes 151 species in 15 genera, being the genus Triatoma (Triatomini tribe) the most numerous and diverse (84 species) and the only one found in the New and Old World [20]. We studied species included in two of the three main groups of this genus: (i) the rubrofasciata group (from Central and North America and Old World species): T. barberi, T. dimidiata, T. lecticularia, T. nitida and T. rubrofasciata; and (ii) the infestans group (from South America): $T$. infestans and T. (Mepraia) spinolai. All these species are important vectors of Chagas disease due to their presence in domestic and peridomestic environments, excepting T. lecticularia which is strictly sylvatic [21].

Geographical origin and cytogenetic traits of the Triatoma species analysed are detailed in Table 1 . These species were selected by their different number of autosomes $\left(18,20\right.$ and 22), male sex systems (XY and $\left.\mathrm{X}_{1} \mathrm{X}_{2} \mathrm{Y}\right)$, and differences in the amount and chromosomal location of autosomal heterochromatin [15, 22-25].

Genomic DNA (gDNA) probes were made from two Triatoma species of the rubrofasciata group: T. rubrofasciata collected in Vietnam (Hanoi city, Tu Liem 
Table 1 Geographical origin and chromosomal traits of seven Triatoma species analysed in the present studyk

\begin{tabular}{|c|c|c|}
\hline $\begin{array}{l}\text { Species and male diploid } \\
\text { chromosome number }(2 n)\end{array}$ & Geographical origin & $\begin{array}{l}\% \text {, chromosome location and size of autosoma } \\
\text { C-heterochromatin }\end{array}$ \\
\hline $\begin{array}{l}\text { T. rubrofasciata } \\
\left(2 \mathrm{n}=22 \mathrm{~A}+\mathrm{X}_{1} \mathrm{X}_{2} \mathrm{Y}\right)\end{array}$ & $\begin{array}{l}\text { Vietnam, Hanoi, Tu Liem district. P. } \\
21^{\circ} 2^{\prime} 48^{\prime \prime} N, 105^{\circ} 44^{\prime} 54^{\prime \prime} E\end{array}$ & $\begin{array}{l}\text { 40\%; } 11 \text { II with C-blocks in both } \\
\text { chromosomal ends [22] }\end{array}$ \\
\hline $\begin{array}{l}\text { T. dimidiata } \\
\left(2 \mathrm{n}=20 \mathrm{~A}+\mathrm{X}_{1} \mathrm{X}_{2} \mathrm{Y}\right)\end{array}$ & $\begin{array}{l}\text { Guatemala, Jutiapa, Carrizal. D. } \\
14^{\circ} 25^{\prime} 48^{\prime \prime} \mathrm{N}, 89^{\circ} 57^{\prime} 28^{\prime \prime} \mathrm{W}\end{array}$ & $10 \% ; 10$ II with C-dots in both ends [23] \\
\hline $\begin{array}{l}\text { T. barberi } \\
\left(2 \mathrm{n}=20 \mathrm{~A}+\mathrm{X}_{1} X_{2} \mathrm{Y}\right)\end{array}$ & $\begin{array}{l}\text { Mexico, Queretaro, La Cueva. P. } \\
20^{\circ} 29^{\prime} 4^{\prime \prime} \mathrm{N}, 100^{\circ} 26^{\prime} 20^{\prime \prime} \mathrm{W}\end{array}$ & 35\%; 10 II with C-blocks in both ends [15] \\
\hline $\begin{array}{l}\text { T. nitida } \\
\left(2 \mathrm{n}=18 \mathrm{~A}+\mathrm{X}_{1} \mathrm{X}_{2} \mathrm{Y}\right)\end{array}$ & $\begin{array}{l}\text { Guatemala, Quiché, Zacualpa, D. } \\
15^{\circ} 1^{\prime} 34^{\prime \prime} \mathrm{N}, 90^{\circ} 52^{\prime} 42^{\prime \prime} \mathrm{W}\end{array}$ & 25\%; 2 II almost entirely C-heterochromatic [15] \\
\hline $\begin{array}{l}\text { T. lecticularia } \\
(2 \mathrm{n}=20 \mathrm{~A}+\mathrm{XY})\end{array}$ & $\begin{array}{l}\text { Insectary CDC (Atlanta). Origin: USA, } \\
\text { Oklahoma, Walkiria. }\end{array}$ & 30\%; 10 II with C-blocks in both ends [15] \\
\hline $\begin{array}{l}\text { T. infestans (non-Andean lineage) } \\
(2 n=20 A+X Y)\end{array}$ & $\begin{array}{l}\text { Argentina, Chaco, Tres Estacas. P. } \\
26^{\circ} 54^{\prime} 30^{\prime \prime} \mathrm{S}, 51^{\circ} 40^{\prime} 23^{\prime \prime} \mathrm{W}\end{array}$ & $\begin{array}{l}\text { 24-30\%; 2-4 II with C-blocks in one or } \\
\text { both ends [24] }\end{array}$ \\
\hline $\begin{array}{l}\text { T. (Mepraia) spinolai } \\
\left(2 \mathrm{n}=20 \mathrm{~A}+\mathrm{X}_{1} \mathrm{X}_{2} \mathrm{Y}\right)\end{array}$ & $\begin{array}{l}\text { Chile, Metropolitan Region of Santiago, Colina. S. } \\
33^{\circ} 11^{\prime} 53^{\prime \prime S}, 70^{\circ} 39^{\prime} 42^{\prime \prime} \mathrm{W}\end{array}$ & 15\%; 10 II with C-dots in both ends [25] \\
\hline
\end{tabular}

Abbreviations: $A$ autosomes, $D$ domestic, $P$ peridomestic, $S$ sylvatic, // bivalents

district, Dai Mo commune, Ngoc Truc village) and $T$. dimidiata from Guatemala (Jutiapa, Carrizal). Genomic DNA isolation for probes generation was made from legs of one adult male individual using the NucleoSpin Tissue kit (Macherey-Nagel Co., Düren, Germany). For probe labelling, total genomic DNA was labelled with biotin-16-dUTP (Roche, Mannheim, Germany) using a Nick Translation Kit (Roche, Shanghai, China), following manufacturer's instructions. To compare the results obtained with these two probes, we applied a third genomic probe ( $T$. infestans) that was already used in a previous paper [16] but applied here for the first time on $T$. rubrofasciata chromosomes.

Chromosome preparations for C-banding and GISH analyses were obtained from males. Gonads were removed from live adult insects, fixed in ethanol: glacial acetic acid mixture $(3: 1)$ and stored at $-20{ }^{\circ} \mathrm{C}$. Squashes were made in a $50 \%$ acetic acid drop, coverslips were removed after being frozen in liquid nitrogen and the slides were air dried and then stored at $4{ }^{\circ} \mathrm{C}$. C-banding was performed according to Panzera et al. [24].

In situ hybridizations were carried out as described by Palomeque et al. [26]. Hybridization solutions were prepared to a final concentration of $0.5-2.0 \mathrm{ng}$ probe/ $\mathrm{ml}$ in $50 \%$ formamide. Hybridization was conducted at $37{ }^{\circ} \mathrm{C}$ overnight. Fluorescence immunological detection was performed using the avidin-FITC/ anti-avidinbiotin system with two amplification rounds. Slides were mounted with Vectashield (Vector, Burlingame, USA). DAPI in the antifade solution was used to counterstain chromosomes. The hybridized chromosomes were observed and photographed using a BX51 Olympus fluorescence microscope equipped with a CCD camera (Olympus DP70) and merged using the DP Manager software. Hybridization pattern for each species was determined by the chromosomal analyses of at least two individuals.

\section{Results}

We observed two chromosomal hybridization patterns: (i) very intense hybridization signals concentrated on specific chromosomal regions or particular chromosomes; and (ii) lower intensity hybridization signals dispersed along all chromosomes (Figs. 1, 2 and 3). In some cases, the lower intensity hybridization signals were masked by the DAPI signal in the merged figures. Table 2 summarises the GISH results described below.

\section{Triatoma rubrofasciata gDNA probe}

Self-GISH results on T. rubrofasciata showed that almost all chromatin presented scattered hybridization signals. Strong hybridization signals were observed in C-heterochromatin regions: chromosomal ends of the 11 half-bivalents plus the $\mathrm{Y}$ chromosome, but neither $\mathrm{X}$ chromosome presented strong hybridizations signals (Fig. 1a). A similar pattern was observed with Cbanding (Fig. 1b). Hybridization of all North American Triatoma species showed strong hybridization signals only on the Y chromosome (Fig. 1c-g), without labelling on other heterochromatic regions (compare Fig. 1e with $\mathrm{f}$, arrows). In $T$. barberi, in addition to the $\mathrm{Y}$ chromosome, one of the two $\mathrm{X}$ chromosomes is also labelled $\left(\mathrm{X}_{1}\right)$ (Fig. 1g).

Triatoma rubrofasciata gDNA probe on chromosomes of South American Triatoma showed differences between the two species analysed. In T. (Mepraia) spinolai, only the $\mathrm{Y}$ chromosome exhibited hybridization signals (Fig. 1h). In $T$. infestans, in addition to the $\mathrm{Y}$ chromosome, 2 to 3 autosomal pairs showed terminal hybridization signals (Fig. 1i). 

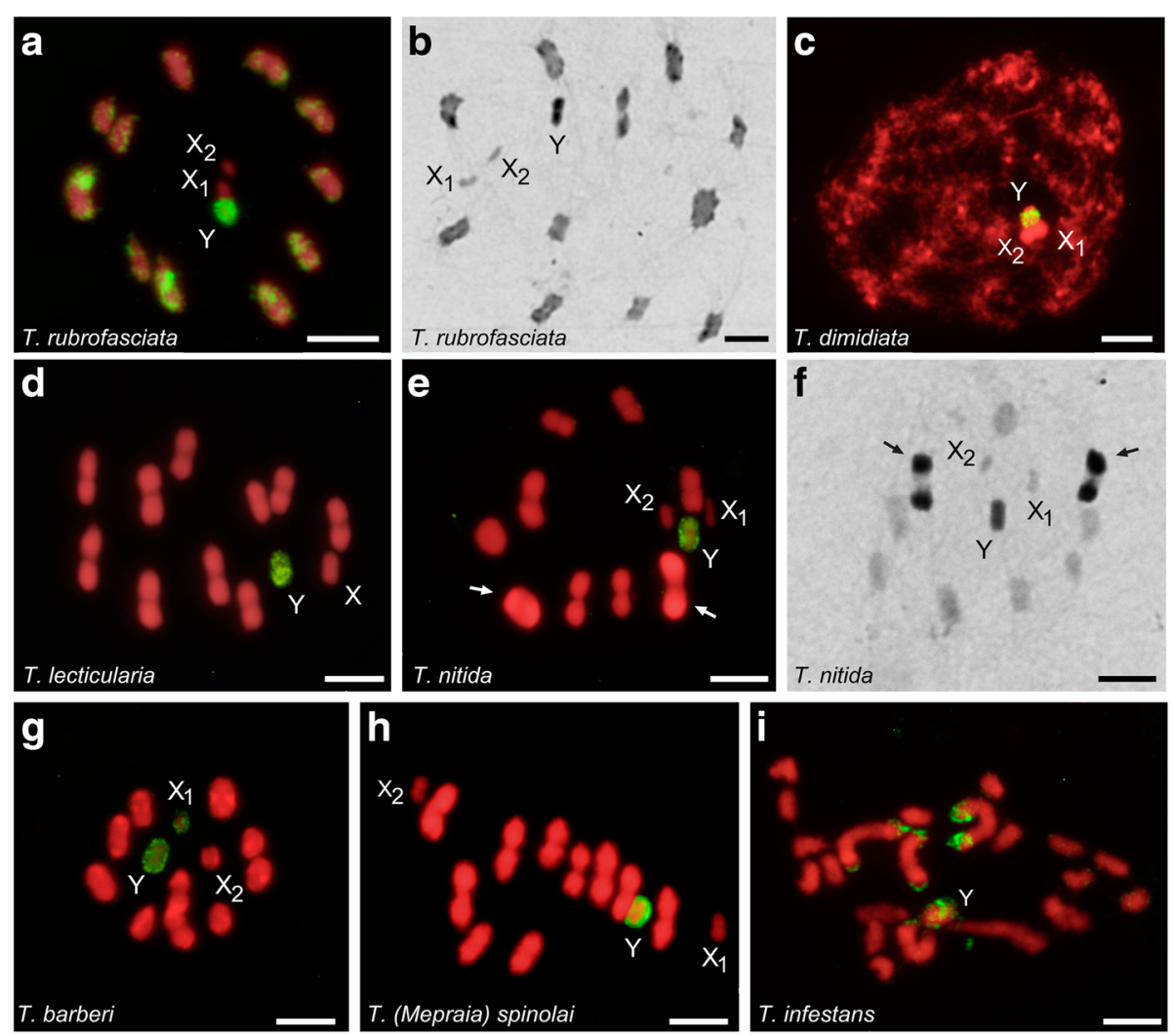

Fig. $1 \mathrm{GISH}$ results using Triatoma rubrofasciata genomic DNA (gDNA) probe (labelled in yellow-green) on male chromosomes of different Triatoma species (labelled in red). a Self-GISH on own chromosomes of T. rubrofasciata $\left(2 n=22 A+X_{1} X_{2} Y\right)$ : Second meiotic metaphase. Hybridization signals appear scattered on all chromatin, but the strongest signals are preferably located at the autosomal chromosome ends plus the $Y$ chromosome. Both X chromosomes did not present hybridization signals. b T. rubrofasciata. First meiotic metaphase (MI) with C-banding. Heterochromatic regions with the same distribution pattern as observed with self-GISH. c T. dimidiata $\left(2 n=20 A+X_{1} X_{2} Y\right)$. Early meiotic prophase. $\mathbf{d}$ T. lecticularia $(2 n=20 \mathrm{~A}+\mathrm{XY})$ : MI. e T. nitida $\left(2 \mathrm{n}=18 \mathrm{~A}+\mathrm{X}_{1} \mathrm{X}_{2} \mathrm{Y}\right): \mathrm{MI}$. In $(\mathbf{c})$ to $(\mathbf{e})$, strong hybridization signals are restricted to the heterochromatic $\mathrm{Y}$ chromosome. f T. nitida: MI with C-banding. The two C-heterochromatic bivalents did not exhibit hybridization signals (compare chromosomes pointed out with arrows in $\mathbf{e}$ and $\mathbf{f}) . \mathbf{g}$ T. barberi $\left(2 \mathrm{n}=20 \mathrm{~A}+\mathrm{X}_{1} \mathrm{X}_{2} \mathrm{Y}\right)$ : MI. $Y$ chromosome and one of the $\mathrm{X}$ chromosomes $\left(\mathrm{X}_{1}\right)$ appear with strong signals. $\mathbf{h} T$. (Mepraia) spinolai $\left(2 \mathrm{n}=20 \mathrm{~A}+\mathrm{X}_{1} \mathrm{X}_{2} \mathrm{Y}\right)$ : Ml. Only the $\mathrm{Y}$ chromosome shows hybridization signals. In (c) to $(\mathbf{h})$, autosomal C-heterochromatic regions appear labelling free. $\mathbf{i}$ T. infestans $(2 n=20 A+X Y)$ : Spermatogonial prometaphase. Strong hybridization signals are observed on the $Y$ chromosome and five autosomes. Scale-bars: 5 Hm. Abbreviations: A, autosomes; Ml, metaphase I

\section{Triatoma dimidiata gDNA probe}

Self-GISH results on $T$. dimidiata showed strong hybridization signals on the $\mathrm{Y}$ chromosome as well as scattered hybridization signals on all chromatin, including both X chromosomes (Fig. 2a). However, on less condensed chromosomes (early meiotic prophase), strong hybridization signals were observed as spots on the chromosomal ends of all autosomes (Fig. 2b). These hybridization signals correspond to the heterochromatic dot regions located on the chromosomal ends observed with C-banding (Fig. 2c). When T. dimidiata gDNA probe was employed on chromosomes of $T$. rubrofasciata and other North American Triatoma species, only the $\mathrm{Y}$ chromosome presented positive hybridization signals (Fig. 2d, e), with the exception of T. barberi, which exhibited the same pattern observed with $T$. rubrofasciata probe (one X chromosome also labelled, data not shown).
In South American Triatoma species, hybridization patterns were the same as the obtained with T. rubrofasciata genomic probe, i.e. only on the $\mathrm{Y}$ chromosome in T. spinolai (Fig. 2f) and 2-3 bivalents plus the $\mathrm{Y}$ chromosome in T. infestans (Fig. 2e).

\section{Triatoma infestans (non-Andean lineage) gDNA probe}

GISH results on T. dimidiata (Fig. 3a) and T. rubrofasciata (Fig. 3b) chromosomes showed strong hybridization signals only on the Y chromosome, while the autosomal heterochromatic regions remain unmarked.

\section{Discussion}

GISH technique and DNA repeat sequences

This paper and the previous one [16] show that triatomine GISH probes reveal two hybridization patterns: scattered hybridization signals along almost all chromatin and 

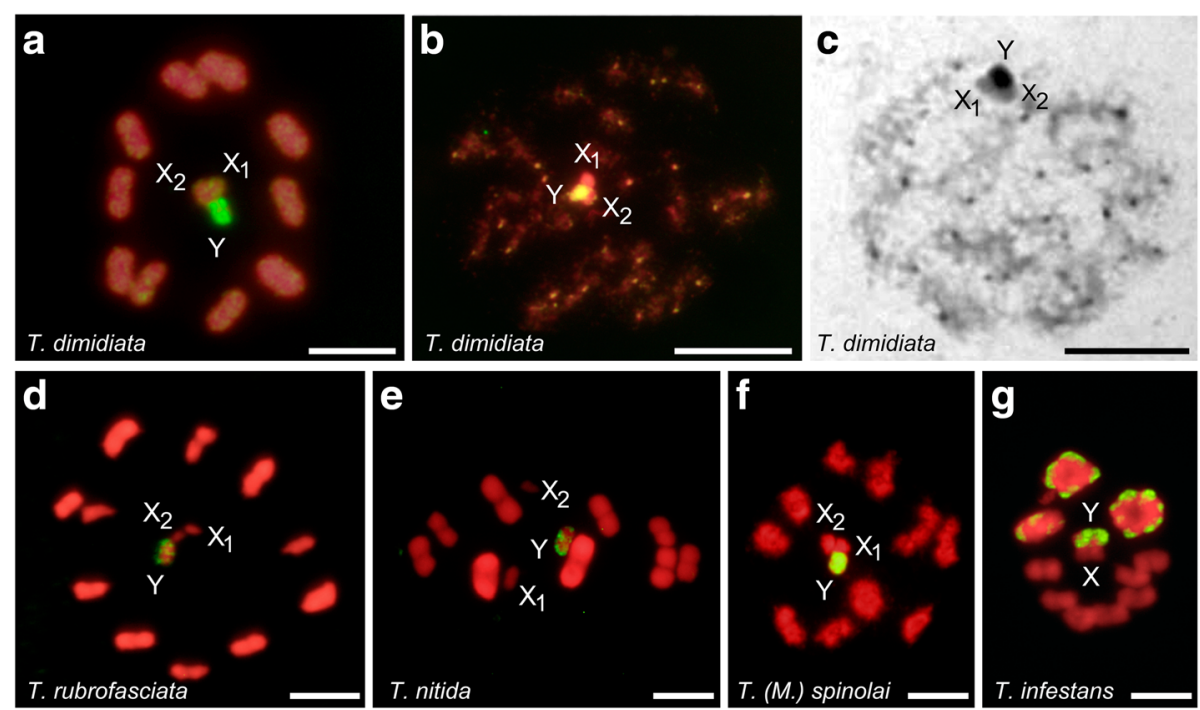

Fig. 2 GISH results using Triatoma dimidiata genomic DNA (gDNA) probe (labelled in yellow-green) on chromosomes of different Triatoma species (labelled in red). a Self-GISH on own chromosomes of $T$. dimidiata $\left(2 n=20 A+X_{1} X_{2} Y\right)$ : Second meiotic metaphase (MII). All chromatin presented scattered hybridization signals, but strong signals were observed only on the $Y$ chromosome. $\mathbf{b} T$. dimidiata: Early meiotic prophase showing dot hybridization signals at the chromosome ends of all autosomes and on the Y chromosome. c T. dimidiata: Early meiotic prophase with C-banding. C-Heterochromatin regions with the same distribution pattern as observed with the genomic probe in $\mathbf{b}$. $\mathbf{d}$ T. rubrofasciata $\left(2 n=22 A+X_{1} X_{2} Y\right)$ : MII. e T. nitida $\left(2 n=18 A+X_{1} X_{2} Y\right)$ : Metaphase I $(M I)$. $f$ T. (Mepraia) spinolai $\left(2 n=20 A+X_{1} X_{2} Y\right)$ : Diakinesis. In c-e, the $Y$ chromosome exhibited strong hybridization signals. $\mathbf{g}$ T. infestans $(2 n=20 A+X Y)$ : MI. Strong hybridizations signals were observed on the $Y$ chromosome and chromosomal ends of three bivalents. Scale-bars: 5 um. Abbreviations: A, autosomes; MI, metaphase l; MII, metaphase II

stronger hybridization signals concentrated on particular chromosomal regions or on the entire chromosomes (Figs. 1, 2 and 3). The stronger signals could be caused by satellite DNA families clustered in long tandem arrays as was seen using specific satDNA probes [27]. Meanwhile, the scattered signals might be produced by small amounts of satellite DNA families [27, 28], or by transposable genetic elements, as has been observed in other insects $[29,30]$.

From GISH results obtained here (Table 2, Figs. 1, 2 and 3) we can draw the following assumptions. First, in the two Self-GISH or Auto-GISH analyses, i.e. T. rubrofasciata genomic probe on $T$. rubrofasciata chromosomes and T. dimidiata gDNA probe on T. dimidiata chromosomes, the strong hybridization signals coincide exactly with the $\mathrm{C}$-heterochromatic regions described for each species (compare Fig. 1a with b, and Fig. 2b with c, respectively). However, when we perform genomic crosshybridizations, i.e. T. rubrofasciata gDNA on T. dimidiata chromosomes (Fig. 1c) and vice versa (Fig. 2d), only strong signals are detected on the $\mathrm{Y}$ chromosome, leaving the $\mathrm{C}$ heterochromatic autosomal regions unmarked. This reveals that the heterochromatic regions of T. rubrofasciata and $T$. dimidiata are constituted by different classes of satellite DNA families, which appear undifferentiated with

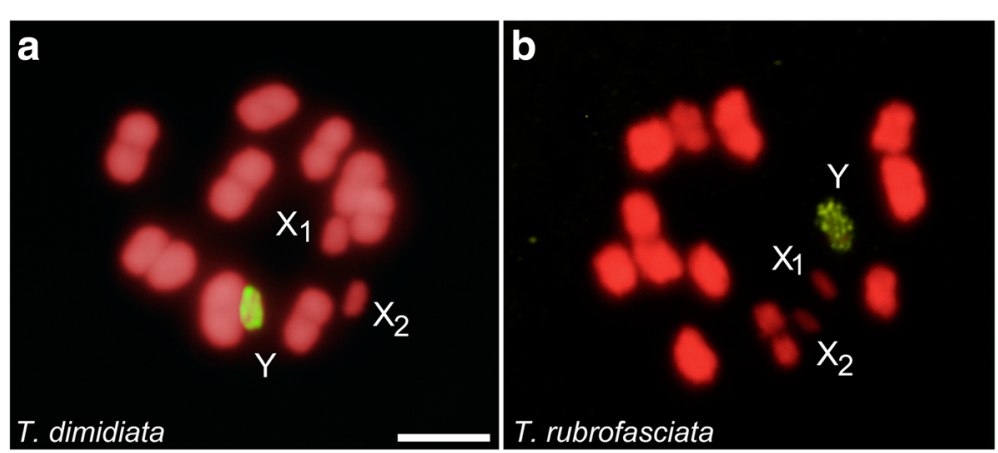

Fig. $3 \mathrm{GISH}$ results using Triatoma infestans genomic DNA (gDNA) probe (labelled in yellow-green) on metaphase I chromosomes (labelled in red) of T. dimidiata (a) and T. rubrofasciata (b). In both species, only the heterochromatic Y chromosome appears with strong hybridization signals, while autosomal heterochromatic regions appear label free. Scale-bars: $5 \mu \mathrm{m}$ 
Table 2 Summary of GISH results using two genomic DNA probes of North American Triatoma on the chromosomes of seven Triatoma species

\begin{tabular}{|c|c|c|}
\hline Species & T. rubrofasciata genomic DNA probe & T. dimidiata genomic DNA probe \\
\hline T. rubrofasciata & $\begin{array}{l}\text { Self-GISH. All autosomal pairs (11 half-bivalents) with strong } \\
\text { hybridization signals in one or both chromosomal ends. } \\
\text { Y chromosome intensively and totally labelled (Fig. 1a) }\end{array}$ & Only Y chromosome (Fig. 2d) \\
\hline T. dimidiata & Only Y chromosome (Fig. 1c) & $\begin{array}{l}\text { Self-GISH. All bivalents (10) with strong hybridization signals } \\
\text { in both chromosomal ends. Y chromosome intensively } \\
\text { and totally labelled (Fig. } 2 a, b)\end{array}$ \\
\hline T. lecticularia & Only Y chromosome (Fig. 1d) & Only Y chromosome. \\
\hline T. nitida & Only Y chromosome (Fig. 1e) & Only Y chromosome (Fig. 2e) \\
\hline T. barberi & Y chromosome plus one $X$ chromosome (Fig. 1g) & Y chromosome plus one $X$ chromosome \\
\hline T. (Mepraia) spinolai & Only Y chromosome (Fig. 1h) & Only Y chromosome (Fig. 2f) \\
\hline $\begin{array}{l}\text { T. infestans } \\
\text { (non-Andean lineage) }\end{array}$ & $\begin{array}{l}2-3 \text { autosomal pairs with strong hybridization signals in } 1 \\
\text { or } 2 \text { chromosomal ends plus the } Y \text { chromosome (Fig. 1i) }\end{array}$ & $\begin{array}{l}2-3 \text { bivalents with strong hybridization signals in } 1 \text { or } 2 \\
\text { chromosomal ends plus the } Y \text { chromosome (Fig. } 2 \mathrm{~g} \text { ) }\end{array}$ \\
\hline
\end{tabular}

C-banding and fluorescence staining [15]. This same conclusion can be extended to the other North American Triatoma (T. lecticularia, $T$. nitida and $T$. barberi) (Fig. 1d-g; Fig. 2e), which have a different amount and chromosomal localization of heterochromatin (Table 1). This evidence is conclusive in showing that, at least in the species here analysed, chromosome diversification in North American Triatoma involved a differential amplification of diverse types of autosomal repeated DNA sequences. This is very different from what has been described for the infestans subcomplex species ( $T$. infestans, $T$. platensis and $T$. delpontei), where these closely related species shared their repeated DNA sequences [16].

Secondly, the hybridization patterns of both genomic probes on $T$. infestans chromosomes showed strong signals on autosomal heterochromatic regions (Figs. 1i and $2 \mathrm{~g}$ ). These results confirm those obtained with South American Triatoma genomic probes, revealing that in the infestans subcomplex the repeated sequences of the $\mathrm{Y}$ chromosome are also present on the autosomal heterochromatic regions [16]. Genomic hybridizations using T. infestans gDNA probe on T. dimidiata [16] and T. rubrofasciata chromosomes (Fig. 3a, b, respectively) showed strong hybridization signals only on the $\mathrm{Y}$ chromosome. These results reveal that autosomal heterochromatic regions of $T$. dimidiata and $T$. rubrofasciata are constituted by different DNA repeats, most probably satDNA families, which are also different from what was observed for the $\mathrm{Y}$ chromosome.

\section{Evolution of sex chromosomes}

In triatomines, sex chromosomes are very well differentiated from autosomes by their distinct behaviour during meiosis. During male meiotic division, $\mathrm{X}$ and $\mathrm{Y}$ chromosomes are asynaptic and achiasmatic, showing an inverted meiosis [31, 32]. Three male sex systems have been reported in Triatominae subfamily: $\mathrm{XY}, \mathrm{X}_{1} \mathrm{X}_{2} \mathrm{Y}$, and $\mathrm{X}_{1} \mathrm{X}_{2} \mathrm{X}_{3} \mathrm{Y}$. The first system is considered ancestral so that the multiple Xs are due to fission processes of the original X [33]. Multiple sex chromosomes have been reported in several triatomine genera including Triatoma species from North and South America [10]. Given that these multiple sex systems appear in triatomine species that are not closely related, it is probable that the fission processes of the $\mathrm{X}$ chromosome have occurred several times during the evolution of this group.

Knowledge about the DNA sequences that composed sex chromosomes in heteropteran species is very limited. Recently, Gallo et al. [34] have analysed the repetitive DNA composition of the $\mathrm{Y}$ and $\mathrm{X}$ chromosomes in several species of the giant water bugs (Heteroptera: Belostomatidae). These authors showed that repetitive DNA was absent on the $\mathrm{Y}$ chromosome while $\mathrm{X}$ chromosomes and autosomes shared repetitive sequences. Our previous results obtained by GISH [16], fluorescent banding [15], X chromosome microdissection [17] and the results displayed here support the idea that the $\mathrm{X}$ and $\mathrm{Y}$ chromosomes in triatomines presented substantial differences in their DNA composition. All of these studies pointed out that the $\mathrm{Y}$ chromosome is extremely conserved among all Triatomini species. It is C-heterochromatic and DAPI positive $[10,15]$, very different to that observed in Belostomatidae. This study confirms that the $\mathrm{Y}$ chromosome in North and South American Triatoma share repeated DNA sequences (Figs. 1, 2 and 3). Very recently we proved that the $\mathrm{Y}$ chromosome in $T$. infestans is constituted by at least two satDNA families [35]. The sequence conservation of the $\mathrm{Y}$ chromosome in a speciose and diverse insect group is very uncommon, and probably represents an ancestral character of Triatomini tribe, such as suggested by Pita et al. [16].

By contrast, the $\mathrm{X}$ chromosome is euchromatic, without fluorescence staining [15] but with dispersed repeated sequences similar to those observed in euchromatic autosomal regions $[17,35]$. Occasionally in some species, like T. barberi (Fig. 1g) and the infestans subcomplex species 
(T. infestans Andean lineage, T. platensis and T. delpontei) [16], the X chromosomes have heterochromatic regions similar to those observed in the $\mathrm{Y}$ chromosome. Probably this sequence homology between the $\mathrm{X}$ and $\mathrm{Y}$ chromosomes are due to repeated sequences transferred from $\mathrm{Y}$ chromosome to the $\mathrm{X}$ chromosome. Since T. barberi and the infestans subcomplex species are evolutionarily distant species, this transference appears to have occurred several times in the evolutionary history of Triatoma, perhaps as a product of secondary differentiation processes. The occurrence of shared sequences between $\mathrm{X}$ and $\mathrm{Y}$ chromosomes have also been seen with the major ribosomal genes in several Triatoma and Rhodnius species [12-14, 36]. The existence of shared repeated sequences between the $\mathrm{X}$ and the $\mathrm{Y}$ chromosomes is not consistent with the accepted notion that the sex chromosomes of Heteroptera do not exchange sequences [32]. Mobilization of repeated sequences between sex chromosomes without recombination or chromosomal pairing could be due to transposition events, as has been suggested in ants [37] and triatomines [13].

Another alternative hypothesis to explain the sequence homology between the $\mathrm{Y}$ chromosome and one of the $\mathrm{X}$ chromosomes in T. barberi is that this heterochromatic $\mathrm{X}_{1}$ chromosome was originated by fission from the $\mathrm{Y}$ chromosome, rather than fissions of an ancestral $X$ as is currently accepted. Considering that the $\mathrm{X}_{1} \mathrm{X}_{2} \mathrm{Y}$ sex system is the only one present in 22 North American Triatoma species currently analysed (except $T$. lecticularia with $\mathrm{XY}$ ) and that the $\mathrm{X}$ chromosome is almost always euchromatic [10], this hypothesis seems improbable but cannot be ruled out.

\section{Conclusions}

Our GISH results allow us to draw the following conclusions: (i) Y chromosome repeated sequences seem to be the only ones shared among all Triatoma species, and even in the whole Triatomini tribe (which also involves six other genera); (ii) the five North American TriatoXma species here analysed did not share their autosomal repeated DNA sequences, in spite of their close evolutionary relationships; and (iii) this divergence in the molecular composition of autosomal repetitive DNA is also observed between North and South American Triatoma. These results suggest that autosomal heterochromatin in triatomines consists of different classes of repeated sequences, probably satDNA, so that during the speciation of this genus amplifications of different repeated DNA families have occurred. Molecular characterization of such repetitive DNA families seems to be an appropriate approach to identify the diversification mechanisms of the repeated sequences and to infer evolutionary relationships in triatomines.

\section{Acknowledgments}

This paper is included in the PhD Thesis of SP (UdelaR-University of Jaén). We also want to thank Carlota Monroy (Universidad de San Carlos, Guatemala) and Ellen Dotson (CDC, Atlanta) for providing some of the insects used in this study. Finally, we are very grateful to Belén Panzera for her assistance with the language review.

\section{Funding}

Academic mobility between Uruguay to Spain for SP and FP were supported by AUIP (Ibero-American University Postgraduate Association), European Programme (Erasmus+/CeiA3) and CSIC (Universidad de la República, UdelaR, Uruguay) and PEDECIBA (Uruguay).

\section{Availability of data and materials}

All data generated or analysed during this study are included in this published article.

\section{Authors' contributions}

$\mathrm{SP}, \mathrm{PL}, \mathrm{JV}, \mathrm{PM}, \mathrm{TP}, \mathrm{KPT}$ and FP conceived and designed the experiments. KPT and FP collected the bugs. SP, PL, JV, PM and FP performed the experiments. $\mathrm{SP}, \mathrm{PL}, \mathrm{JV}, \mathrm{PM}, \mathrm{TP}$ and FP analyzed the data. PL, TP, KPT and FP contributed reagents/materials/analysis tools. SP, PL, TP and FP wrote the manuscript. All authors read and approved the final manuscript.

Ethics approval and consent to participate Not applicable.

\section{Consent for publication}

Not applicable.

\section{Competing interests}

The authors declare that they have no competing interests.

\section{Publisher's Note}

Springer Nature remains neutral with regard to jurisdictional claims in published maps and institutional affiliations.

\section{Author details}

${ }^{1}$ Sección Genética Evolutiva, Facultad de Ciencias, Universidad de la República, Calle Iguá 4225, 11400 Montevideo, Uruguay. ${ }^{2}$ Departamento de Biología Experimental, Área de Genética, Universidad de Jaén, Paraje Lagunillas s/n, 23071 Jaén, Spain. ${ }^{3}$ Center for Molecular Biology, IRD, Duytan University, Danang, Vietnam.

Received: 3 June 2017 Accepted: 28 August 2017

Published online: 06 September 2017

\section{References}

1. Palomeque T, Lorite P. Satellite DNA in insects: a review. Heredity. 2008;100:564-73.

2. Plohl M, Meštrović N, Mravinac B. Satellite DNA evolution. Genome Dyn 2012;7:126-52.

3. Meštrović N, Mravinac B, Pavlek M, Vojvoda-Zeljko T, Šatović E, Plohl M. Structural and functional liaisons between transposable elements and satellite DNAs. Chromosom Res. 2015;23:583-96.

4. Shapiro JA, von Sternberg R. Why repetitive DNA is essential to genome function. Biol Rev. 2005:80:227-50.

5. Mtreirek R, Gueguen N, Jensen S, Brasset E, Vaury C. Drosophila heterochromatin: structure and function. Curr Opin Insect Sci. 2014;1:19-24.

6. Hughes SE, Hawley RS. Heterochromatin: a rapidly evolving species barrier. PLoS Biol. 2009:7:e1000233.

7. Ferree PM, Barbash DA. Species-specific heterochromatin prevents mitotic chromosome segregation to cause hybrid lethality in Drosophila. PLOS Biol. 2009:7:e1000234.

8. Mola LM, Papeschi AG. Holokinetic chromosomes at a glance. J Basic App Genet. 2006;17:17-33.

9. World Health Organization 2017. Chagas disease (American trypanosomiasis). http://www.who.int/mediacentre/factsheets/fs340/en/index.html. Accessed 22 May 2017. 
10. Panzera F, Pérez R, Panzera Y, Ferrandis I, Ferreiro MJ, Calleros L. Cytogenetics and genome evolution in the subfamily Triatominae (Hemiptera, Reduviidae). Cytogenet Genome Res. 2010;128:77-87.

11. Panzera F, Ferrandis I, Ramsey J, Salazar-Schettino PM, Cabrera M, Monroy C, et al. Genome size determination in Chagas disease transmitting bugs (Hemiptera-Triatominae) by flow cytometry. Am J Trop Med Hyg. 2007;76:516-21.

12. Panzera Y, Pita S, Ferreiro MJ, Ferrandis I, Lages C, Pérez R, et al. High dynamics of rDNA cluster location in kissing bug holocentric chromosomes (Triatominae, Heteroptera). Cytogenet Genome Res. 2012;138:56-67.

13. Pita S, Panzera F, Ferrandis I, Galvão C, Gómez-Palacio A, Panzera Y. Chromosomal divergence and evolutionary inferences in Rhodniini based on the chromosomal location of ribosomal genes. Mem Inst Oswaldo Cruz. 2013;108:376-82.

14. Pita S, Lorite P, Nattero J, Galvão C, Alevi KCC, Teves SC, et al. New arrangements on several species subcomplexes of Triatoma genus based on the chromosomal position of ribosomal genes (Hemiptera-Triatominae). Infect Genet Evol. 2016;43:225-31.

15. Bardella VB, Pita S, Vanzela ALL, Galvão C, Panzera F. Heterochromatin base pair composition and diversification in holocentric chromosomes of kissing bugs (Hemiptera, Reduviidae). Mem Inst Oswaldo Cruz. 2016;111:614-24.

16. Pita S, Panzera F, Sanchez A, Panzera Y, Palomeque T, Lorite P. Distribution and evolution of repeated sequences in genomes of Triatominae (Hemiptera: Reduviidae) inferred from genomic in situ hybridization. PLoS One. 2014;9:e114298.

17. Pita S, Panzera F, Sánchez A, Palomeque T, Lorite P. Chromosome painting in triatomine insects reveals shared sequences between $X$ chromosomes and autosomes. J Med Entomol. 2017:54:44-9.

18. Bressa MJ, Papeschi AG, Vítková M, Kubíčková S, Fuková I, Pigozzi MI, et al. Sex chromosome evolution in cotton stainers of the genus Dysdercus (Heteroptera: Pyrrhocoridae). Cytogenet Genome Res. 2009;125:292-305.

19. Dalíková M, Zrzavá M, Kubíčková S, Marec F. W-enriched satellite sequencein the Indian meal moth, Plodia interpunctella (Lepidoptera, Pyralidae). Chromosom Res 2017. doi: 10.1007/s10577-017-9558-8

20. Justi SA, Galvão C. The evolutionary origin of diversity in Chagas disease vectors. Trends Parasitol. 2017;33:42-52.

21. Lent H, Wygodzinsky P. Revision of the Triatominae (Hemiptera: Reduviidae) and their significance as vectors of Chagas disease. Bull Am Mus Nat Hist. 1979;163:123-520.

22. Dujardin JP, Thi KP, Xuan LT, Panzera F, Pita S, Schofield CJ. Epidemiological status of kissing-bugs in South East Asia: a preliminary assessment. Acta Trop. 2015;151:142-9.

23. Panzera F, Ferrandis I, Ramsey J, Ordonez R, Salazar-Schettino PM, Cabrera M, et al. Chromosomal variation and genome size support existence of cryptic species of Triatoma dimidiata with different epidemiological importance as Chagas disease vectors. Tropical Med Int Health. 2006;11:1092-103.

24. Panzera F, Dujardin JP, Nicolini P, Caraccio MN, Rose V, Tellez T, et al. Genomic changes of Chagas disease vector, South America. Emerg Infect Dis. 2004;10:438-46.

25. Calleros L, Panzera F, Bargues MD, Monteiro F, Klisiowicz DR, Zuriaga M, et al. Systematics of Mepraia (Hemiptera-Reduviidae): cytogenetic and molecular variation. Infect Genet Evol. 2010;10:21-8.

26. Palomeque T, Muñoz-López M, Carrillo JA, Lorite P. Characterization and evolutionary dynamics of a complex family of satellite DNA in the leaf beetle Chrysolina carnifex (Coleoptera, Chrysomelidae). Chromosom Res. 2005;13:795-807.

27. Ruiz-Ruano FJ, López-León MD, Cabrero J, Camacho JP. High-throughput analysis of the satellitome illuminates simple sequence tandem repeat DNA evolution. Sci Rep. 2016;6:28333.

28. Pavlek M, Gelfand Y, Plohl M, Meštrović N. Genome-wide analysis of tandem repeats in Tribolium castaneum genome reveals abundant and highly dynamic tandem repeat families with satellite DNA features in euchromatic chromosomal arms. DNA Res. 2015;22:387-401.

29. Lorite P, Maside X, Sanllorente O, Torres MI, Periquet G, Palomeque T. The ant genomes have been invaded by several types of mariner transposable elements. Naturwissenschaften. 2012;99:1007-20.

30. Palomeque T, Sanllorente O, Maside X, Vela J, Mora P, Torres MI, et al Evolutionary history of the Azteca-like mariner transposons and their host ants. Naturwissenschaften. 2015;102:44.
31. Solari AJ. Autosomal synaptonemal complexes and sex chromosomes without axes in Triatoma infestans (Reduviidae, Hemiptera). Chromosoma. 1979;72:225-40

32. Ueshima N, Hemiptera II. Heteroptera. In: John B, editor. Animal Cytogenetics. Vol. 3, Insecta 6. Berlin-Stuttgart. Gebrüder Bornträger; 1979. p. 117.

33. Ueshima N. Cytotaxonomy of the Triatominae (Reduviidae: Hemiptera). Chromosoma. 1966;18:97-122.

34. Gallo RB, Aguiar RCM, Ricietto APS, Vilas-Bôas LA, da Silva CRM, Ribeiro JRI, et al. A new approach to chromosomal evolution in the giant water bug (Heteroptera: Belostomatidae). J Heredity. 2017;108:184-93.

35. Pita S, Panzera F, Mora P, Vela J, Cuadrado A, Sánchez A, et al. Comparative repeatome analysis on Triatoma infestans Andean and non-Andean lineages, main vector of Chagas disease. PLoS One. 2017;12(7):e0181635.

36. Panzera F, Pita S, Nattero J, Panzera Y, Galvão C, Chavez T, et al. Cryptic speciation in the Triatoma sordida subcomplex (Hemiptera, Reduviidae) revealed by chromosomal markers. Parasit Vectors. 2015;8:495.

37. Palomeque T, Carrillo JA, Muñoz-López M, Lorite P. Detection of a marinerlike element and a miniature inverted-repeat transposable element (MITE) associated with the heterochromatin from ants of the genus Messor and their possible involvement for satellite DNA evolution. Gene. 2006:371:194-205.

\section{Submit your next manuscript to BioMed Central and we will help you at every step:}

- We accept pre-submission inquiries

- Our selector tool helps you to find the most relevant journal

- We provide round the clock customer support

- Convenient online submission

- Thorough peer review

- Inclusion in PubMed and all major indexing services

- Maximum visibility for your research

Submit your manuscript at www.biomedcentral.com/submit
) Biomed Central 